\title{
Conflitos envolvendo colonizadores e indígenas em áreas territoriais da bacia hidrográfica do Taquari-Antas, Rio Grande do Sul
}

\section{Conflicts between colonists and indians in territorial areas of Taquari-Antas hydrographic basin, Rio Grande do Sul, Brazil}

Moisés Ilair Blum Vedoy - Mestrando no Programa de Pós-Graduação em Ambiente e Desenvolvimento da Universidade do Vale do Taquari (Univates), Lajeado (RS). Graduação em História pela mesma instituição. E-mail: moisesvedoy@gmail.com

Luis Fernando da Silva Laroque - Doutor em História pela Universidade do Vale do Rio dos Sinos (UNISINOS). Professor e pesquisador do Programa de Pós-Graduação em Ambiente e Desenvolvimento e do Curso de Graduação em História da Universidade do Vale do Taquari (Univates), Lajeado (RS). E-mail: 1flaroque@univates.br

Neli Teresinha Galarce Machado - Doutora em Arqueologia pela Universidade de São Paulo (USP). Professora do Programa de Pós-Graduação em Ambiente e Desenvolvimento e do Curso de Graduação em História da Universidade do Vale do Taquari (Univates), Lajeado (RS). E-mail: ngalarce@univates.br

\section{Resumo}

O objetivo do artigo consiste em analisar os conflitos entre indígenas e colonizadores envolvendo o estabelecimento de sesmarias e fazendas em territórios da bacia hidrográfica do rio TaquariAntas, na primeira metade do século XIX. Trata-se de um estudo qualitativo recorrendo à abordagem etno-histórica para a revisão bibliográfica e análise das fontes documentais encontradas no Arquivo Histórico e Público do Rio Grande do Sul. Inicialmente, apresenta-se o avanço da Frente de Expansão do Estado Nacional brasileiro em direção aos territórios da bacia hidrográfica do Taquari-Antas, por meio do estabelecimento de sesmarias e fazendas erguidas em tradicionais territórios dos indígenas Kaingang. Na sequência, analisam-se os conflitos ocorridos entre os Kaingang e os membros da frente de expansão ao longo das décadas de 1830 e 1840. Constatou-se que os conflitos ocorridos se deram em decorrência de lógicas culturais distintas entre os grupos envolvidos, pois, enquanto, para os Kaingang, os territórios e seus recursos eram concebidos como algo coletivo, para os colonizadores eram tomados como algo privado.

\section{Palavras-chave}

Indígenas. Colonizadores. Frente de Expansão. Taquari-Antas

\begin{abstract}
The purpose of this paper consists in analyzing conflicts between Indians and colonists in regard to the establishment of sesmarias and farms in the area of Taquari-Antas hydrographic basin in early nineteenth century. The following text is a qualitative study which is based on ethnohistorical approach in order to review literature and to analyze historic sources found at Arquivo Histórico do Rio Grande do Sul. Initially we present the expansion of the Brazilian State and society towards the territories of Taquari-Antas hydrographic basin through the establishment of sesmarias and farms that were built in traditional Kaingang territories. In the sequence, we analyze the clonficts between the Kaingang and the members of the expansion over the years of 1830 and 1840. It was verified that the conflicts occurred due to the cultural differences between the groups involved, because, whilst to the Kaingang the territories and their resources were conceived as something collective, to the settlers were taken as something private.
\end{abstract}

\section{Keywords}

Indians. Colonists. Expansion. Taquari-Antas. 


\section{INTRODUÇÃO}

A temática do estudo aborda os contatos interétnicos entre colonizadores e indígenas em territórios da bacia hidrográfica do Taquari-Antas, província de São Pedro do Rio Grande do Sul, durante o século XIX, sobretudo no que se refere à disputa pelo território. Com base nos registros documentais do período, procurou-se analisar alguns destes conflitos levando em consideração os aspectos culturais dos sesmeiros, fazendeiros e indígenas Kaingang.

Vale salientar que, no século XIX, o território em análise era caracterizado como zona de fronteira interétnica, que culminou com o conflito entre os Kaingang e a frente de expansão, esta patrocinada pelo Estado Nacional brasileiro. O objetivo do artigo consiste em analisar os conflitos entre indígenas e colonizadores envolvendo o estabelecimento de sesmarias e fazendas em territórios da bacia hidrográfica do rio Taquari-Antas, na primeira metade do século XIX. Trata-se de um estudo qualitativo recorrendo à abordagem etno-histórica para a revisão bibliográfica e análise das fontes documentais encontradas no Arquivo Histórico do Rio Grande do Sul (AHRS) e Arquivo Público do Rio Grande do Sul (APRS). Informamos que a etno-história utilizada neste trabalho é concebida como uma abordagem metodológica no tratamento e na análise das fontes, a fim de relativizar a história contada pelo colonizador, que trata as sociedades indígenas como simples e estáticas. A tarefa, portanto, é trabalhar no sentido de reverter essa situação (CAVALCANTI, 2011; LAROQUE et al., 2015).

\section{A FRENTE DE EXPANSÃO E O ESTABELECIMENTO DE SESMARIAS E FAZENDAS EM TERRITÓRIOS DA BACIA HIDROGRÁFICA DO TAQUARI-ANTAS}

A expansão lusitana em direção ao Brasil meridional pode ser observada desde as fundações da Colônia do Sacramento (1680) e de Laguna (1684); contudo, intensificou-se com a distribuição de sesmarias e o incentivo à chegada e o estabelecimento dos primeiros casais açorianos. Em relação à política colonial das sesmarias, ao longo do período Colonial, conforme Gorender (1992, p. 293), "a Coroa reconhecia a futilidade de uma colonização aristocrática, pois o que importava era a valorização econômica imediata do território brasileiro”. 
Portanto, a doação de sesmarias no Rio Grande do Sul do final do século XVIII e início do XIX seguia esta mesma linha de raciocínio, concedendo as sesmarias aos beneficiários, conforme a sua capacidade de manter e valorizar as suas possessões.

Com base em Christilino (2004), acredita-se que, em meados do final do século XVIII, garantidas as possessões em torno dos Campos de Viamão, Porto dos Casais e Santo Antônio da Patrulha, o "Rio Grande do Sul português" possuía duas fronteiras em expansão, demarcadas pelas povoações nas localidades de Rio Grande e Rio Pardo. A bacia hidrográfica do Taquari-Antas localizava-se em território de abrangência do povoado de Rio Pardo, espaço que urgia ocupação por representantes dos interesses lusitanos. Salienta-se que, nestes territórios, já havia habitantes, os indígenas Kaingang, que possuíam uma lógica de ocupação destes espaços até então independente dos interesses das coroas ibéricas, bem como, as denominações e demarcações oriundas deste contexto.

Assim, aponta-se que os territórios localizados em áreas do rio TaquariAntas, inseridos dentro do cenário fronteiriço do Rio Grande do Sul, desde o final do século XVIII, passaram a ser de interesse do governo da província de São Pedro do Rio Grande do Sul. Em virtude das incursões espanholas/castelhanas, os territórios onde se encontra o arroio Castelhano, atualmente na jurisdição do município de Venâncio Aires, apresentaram-se como áreas estratégicas para proteção militar contra as investidas castelhanas.

Não foi em vão que parte das tropas daquela vila se deslocou à última para combater os castelhanos ainda em curso de viagem. Isto, além de mostrar a importância estratégica da região para a proteção militar de Rio Pardo, alertou o governo português à necessidade de povoar mais densamente àquela região [...] (CHRISTILINO, 2004, p. 26).

Salienta-se ainda que não se tratava somente para a defesa contra os castelhanos, mas também era um espaço que, "a partir das vilas de Rio Pardo e de Rio Grande, os portugueses seguiram sua marcha rumo ao oeste adentrando, tomando e assegurando posições nas áreas de domínio espanhol" (TIBURI, 2011, p. 46).

Portanto, a ocupação dos territórios da bacia hidrográfica do TaquariAntas por parte de integrantes da Coroa portuguesa estava ligada à ocupação já referida dos campos de Viamão ${ }^{1}$. Sendo assim, podem ser compreendidos como

\footnotetext{
Os Campos de Viamão serviam como denominação para uma expressiva parte do extremo sul do Brasil. Conforme Kuhn (2002), no século XVIII os demarcadores dos Campos de Viamão,
} 
uma "[...] extensa faixa de terra que compunha um quadrilátero, cujo flanco leste alcançava pelo menos a altura do Taquari, em meados do século XVIII" (TIBURI, 2011, p. 33). Vale salientar que, embora os Campos de Viamão fossem conhecidos há muito tempo por parte do governo português, o seu intensivo povoamento só se sucedeu em virtude dos embates entre Portugal e Espanha e a assinatura do Tratado de Tordesilhas.

A grande "arrancada" no povoamento de Viamão se deu entre finais da década de 1740 e princípios da década de 1750, quando o número de fogos mais do que duplicou, em um período ainda anterior às migrações açorianas, que modificaram completamente o padrão demográfico da freguesia (KUHN, 2004, p. 48-49).

No século XVIII, quatro bairros rurais, assim chamados, designavam os entornos do rio dos Sinos, Caí e Taquari, que, em 1757, tornar-se-ia Triunfo, que, por sua vez, estava composto por vinte e quatro "fogos", o que demonstra já um grande índice demográfico, visto que, conforme o levantamento de Kuhn (2004), com base nos dados paroquiais de 1778, em toda a freguesia de Viamão existiam em torno de 187 fogos durante este período. "A extensa freguesia aparece dividida em dez 'distritos' ou 'bairros rurais', na verdade as diversas localidades que compunham os vastos Campos de Viamão" (KUHN, 2004, p. 52).

O interesse português não se resguardava somente na disputa política com a coroa espanhola pelos espaços sulinos, visto que a economia por meio da produção do charque se desenvolvia a passos largos e se mostrava a principal fonte de renda aos grandes estancieiros do Rio Grande do Sul, bem como, do comércio de escravos.

O charque havia se tornado dominante nas exportações sulinas já na década de 1790, fornecendo um impulso ainda maior a esse processo. A pecuária que se expandia e a exportação de charque que lhe dava vazão, ao longo de todo o século XIX, foram atividades mercantis voltadas, primordialmente, para o mercado interno brasileiro. [...] De lá, adquiria escravos e produtos importados. Em uma ligação que ganhou maior expressão no início do século XIX e manteve-se firme nos três primeiros quartéis daquele século, o charque rio-grandense desempenhou papel relevante na reprodução das relações escravistas das áreas de plantation articuladas com as praças mercantis para as quais a carne salgada era comercializada (FARINAT'TI, 2007, p. 68, grifo do autor). 
Este cenário, que caracterizava o Rio Grande do Sul como uma região de fronteira, deixava a Coroa portuguesa em constante estado de alerta. Ou seja, nas últimas décadas do século XVIII, o interesse econômico pelo território acentuase ainda mais e continua no decorrer do século seguinte durante o período do Império brasileiro. A solução foi a incorporação social de uma elite militar que garantisse a soberania sobre o território.

Através da política de redistribuição de terras iniciada a partir de 1780, quando começou o processo de expropriação dos antigos proprietários, como os colonos açorianos ou mesmo detentores de sesmarias da primeira fase de expansão da fronteira, em função da nova elite enriquecida (PESAVENTO, 1986, p. 32).

No intuito de ocupar os espaços em direção a oeste, ao longo das bacias hidrográficas do Jacuí, Pardo e do Taquari-Antas, considerados espaços "vazios", a Coroa passou a conceder sesmarias, que eram lotes de terras "cuja extensão máxima deveria ser de três léguas quadradas, ou 13.068 hectares" (OSÓRIO, 2006, p. 158). Estes sesmeiros passaram a estabelecer fazendas nestas áreas concedidas, nas quais os territórios do Taquari-Antas mantinham um modo de produção condizente com o contexto escravocrata do Brasil do século XVIII. Prática que, no Rio Grande do Sul, se manteria por boa parte do século XIX, visto que o governo imperial, por razões militares, era obrigado a ceder às ambições dos chefes locais, dando-lhes terras, fazendo "vista grossa" aos abusos de poder que se registravam (PESAVENTO, 1986).

Considera-se que esta política de doação de sesmarias do governo tenha se intensificado com o intuito de resguardar o território dos interesses espanhóis, muito em virtude do ataque ocorrido na década de 1760, em localidades como Rio Grande e áreas limítrofes, liderado por D. Pedro de Cevallos, bem como, das investidas castelhanas em direção ao território do Taquari-Antas. O trabalho de Christilino (2004, p. 27) acentua este conturbado contexto do final do século XVIII, para compreender a ocupação destes espaços em termos militares, ao informar que os "inimigos platinos descobriram o ponto nevrálgico da defesa de Rio Pardo: a possibilidade de incursão pelas áreas serranas do Vale do Taquari”.

A doação de sesmarias e a manutenção social da elite por meio dos dotes matrimoniais foi o modo pelo qual se dava a ocupação territorial a exemplo de Jerônimo de Ornellas e Francisco Pinto Bandeira, os quais direcionaram as suas possessões em direção a oeste, a partir de Porto Alegre. Conforme Kuhn (2004), Pinto Bandeira se destacava como sendo um dos maiores proprietários de 
escravos no rol dos confessados da paróquia da Freguesia de Viamão do ano de 1751, como "um dos mais relevantes membros da elite local e dono de 20 cativos neste recenseamento" (KUHN, 2004, p. 51).

Em relação aos territórios da bacia hidrográfica do Taquari-Antas, Christilino (2004) acentua que estas sesmarias foram propiciadas pela política de Gomes Freire de Andrade, governador da capitania do Rio de Janeiro, em ocupar áreas da bacia do rio Jacuí. Conforme Tiburi (2011, p. 36), somente "com o Tratado de Madrid (1750), com a construção do forte Jesus Maria José, em Rio Pardo, que o governo promove a ocupação efetiva do vale do Jacuí para dar suporte à fronteira de Rio Pardo".

Especificamente para o recorte territorial em análise, é importante enfatizar que, já na década de 1750, foram doadas terras no território que, posteriormente, viria a ser designado como Vale do Taquari dentro do contexto fronteiriço da fundação de Rio Pardo.

As fundações destas duas povoações foram propiciadas pela política do Governador da Capitania do Rio de Janeiro, Gomes Freire de Andrade, em ocupar a Bacia do Rio Jacuí, concedendo sesmarias de terras ainda na década de 1750 ao Capitão Francisco Xavier de Azambuja, Pedro Lopes Soares e Antonio Brito Leme no Vale do Taquari (CHRISTILINO, 2004, p. 25).

Ainda, em relação a este período, foi concedido por parte de Gomes Freire de Andrade ao capitão Francisco Machado Fagundes da Silveira, no ano de 1762, na margem direita do rio Taquari, conforme segue:

Campos nas várzeas do Rio Taquary, que confrontam: Pelo Norte com a Serra; ao Sul com uns morros e mattos que dividião a Fazenda de Lourenço Bicudo; a Oeste com uma grande várzea de mattos que confrontam com o potreiro de Cosme da Silveira, e pela parte de Leste com o rio Taquary (PORTO ALEGRE, 1762, n.p).

Outro registro é a disposição da sesmaria de Francisco da Silva, concedida por José Marcellino de Figueiredo no ano de 1780. Localizada nos "Campos em Taquary, à margem do rio desse nome, fazendo divisa com os de João Francisco" (PORTO ALEGRE, 1780, n.p).

Ainda, no século XVIII, houve a doação de terras onde atualmente localiza-se o município de Cruzeiro do Sul, segundo a disposição da sesmaria, de José da Silva Lima e seus irmãos, concedida pelo Conde de Rezende, no ano de 1798 . 
Terras a margem do rio Taquary, que confrontam: Pelo Sul com o arroio chamado "Castelhano"; pelo Norte com o arroio Sampaio; a Oeste com um sertão devoluto e pelo Leste faz frente ao dito rio Taquary (PORTO ALEGRE, 1798, n.p).

A frente de expansão em direção aos espaços do Taquari-Antas deu-se a partir dos povoados de São José do Taquari, localizados à margem esquerda oposta ao povoado de Santo Amaro, que ficava à margem direita, que, desde a década de 1760, recebia levas de casais açorianos. Como visto, os espaços da bacia hidrográfica do Taquari-Antas, desde o início da colonização, faziam parte da freguesia de Viamão. Posteriormente, a partir da década de 1740, passaram a fazer parte da Freguesia de Triunfo, até a emancipação da Vila de Taquari no século XIX. Em relação ao final do século XVIII, conforme Christilino (2004), os ocupantes dos territórios da bacia hidrográfica do Taquari-Antas, embora política e economicamente secundários, com o passar do tempo, tomaram "importantes posições junto aos órgãos de poder em função das suas alianças, especialmente matrimoniais, com os membros da elite principal da Província” (CHRISTILINO, 2004, p. 29). Neste sentido, ainda temos:

A presença de paulistas, Lagunenses e Viamonenses, desde os primórdios do Tratado de Madrid (1750), já eram notados nas margens do Jacuí, entre eles os genros de Jerônimo de Ornellas, Cosme Silveira, paulista, um dos primeiros povoadores de Viamão e o Capitão Pedro Lopes Soares, genro de Dyonisio Rodrigues Mendes, lagunistas, todos ligados aos troncos seculares do Rio Grande. Os citados ganharam sesmarias na região conhecida como fronteira de Rio Pardo (TIBURI, 2011, p. 51).

Isto porque a política de distribuição das sesmarias, acelerada pelo Tratado de Madrid (1750), e as disputas entre as coroas ibéricas na segunda metade do século XVIII, possibilitou a expansão fundiária de uma sociedade hierárquica que estendia seu patrimônio por meio de uma rede matrimonial. Sendo assim, a partir do século XIX, é possível verificar uma intensificação da doação de sesmarias em territórios da bacia hidrográfica do Taquari-Antas, conforme mapa (Figura 1). 
Figura 1 - Mapa das sesmarias e das fazendas em territórios da bacia hidrográfica Taquari-Antas

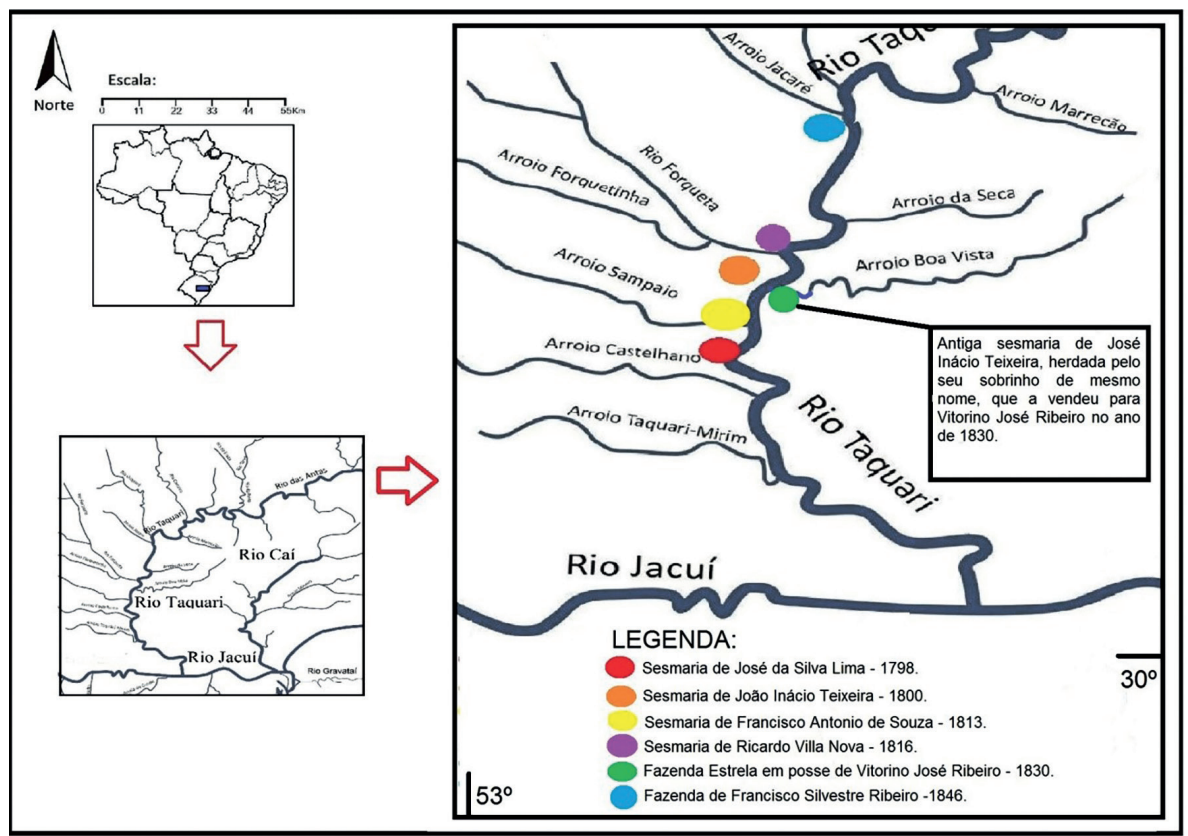

Fonte: Elaboração do autor a partir do software I3GEO. Disponível em: <http:/ /enola.

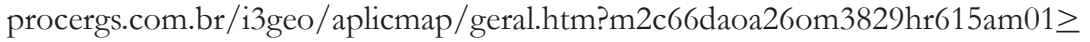

Considerando as agitações num cenário maior, que envolvia a relação da colônia com a área do Prata, pois os "conflitos que envolviam as fronteiras lusobrasileiras, nesta região, aumentavam constantemente os números de concessões de terras como recompensas pelos serviços militares prestados pelos milicianos" (CHRISTILINO, 2004, p. 34). Neste cenário, também é preciso considerar a integração econômica destes espaços, tendo em vista "a dependência das vias naturais de transporte e comunicação se fazia através dos rios navegáveis, forma mais rápida e de pequeno custo para os padrões da época" (TIBURI, 2011, p. 40).

Ilustra a situação a doação de terras pelo Conde de Rezende ao capitão Manoel Jesus Ferreira, no ano de 1800.

Campos nos galhos ocidentais do rio Taquary, e que se dividem: a Leste por um arroio, com o Potreiro das Mulas, que houve em dote, e por outro arroio com os campos do faxinal do Alferes Francisco Machado Fagundes; ao Norte, por outro arroio, galhos dos antecedentes, dividindo o faxinal dos Alferes Manoel Roiz; ao Sul, por uma vertente, com mattos que saem da Serra, e a Oeste com os mattos da falda da Serra (PORTO ALEGRE, 1800a, n.p). 
Ainda, no ano de 1800, há o registro da doação de terras aos irmãos José Inácio Teixeira e João Inácio Teixeira, conforme o mapa das fazendas atualmente localizadas, respectivamente, em territórios dos municípios de Estrela e Lajeado. Na carta de doação de sesmaria de João Inácio Teixeira, temos o seguinte:

Dom João por Graça de Deos Princípe Regente de Portugal e dos Algarves e de além Mais em Africa de Guiné e da Conquista Navegação e Comércio da Ethiopia, Arabia Persia e da Índia Faz-se saber os que esta Minha Carta de Confirmação de Sesmaria por parte de João Ignácio Teixeira [...] confrontando pella frente com o Rio Taquari (PORTO ALEGRE, 1800b, n.p).

Observa-se que João Inácio Teixeira, irmão de José Inácio, havia adquirido uma sesmaria. Conforme Schierholdt (1993) e Christilino (2004), ambos eram moradores da vila de Porto Alegre, que, juntos, formaram uma sociedade com o objetivo de aumentarem as suas possessões territoriais através da aquisição de sesmarias, a exemplo da fazenda dos Conventos e a fazenda Estrela, respectivamente localizadas nos atuais territórios de Lajeado e Estrela, conforme o mapa (Figura 1).

As doações de sesmarias eram feitas por meio de requerimentos, que poderiam levar anos até a definição da legitimação da posse da terra, como a de Francisco Antônio de Souza, que deu entrada no ano de 1809, conforme segue:

Fazemos saber que Francisco Antônio de Souza morador nesta Capitania do Rio Grande de São Pedro do Rio Grande do Sul, propor a S.A.R. hum requerimento omologado pedindo ao Senhor houvesse G. Cem dar-lhe huma Datas de sesmar Mattos sita na margem Ocidental do rio Taquary. Com trez mil e cinquenta braças de frente com o mesmo Rio, defundo para o Sertão. Confrontando pelo Sul as José da Silva Lima e seus irmão, e pelo Norte com as do falecido João Bernardes [...] (PORTO ALEGRE, 1809 , n.p).

Transcorrendo um período de quatro anos, ou seja, no ano de 1813, é dado o retorno de confirmação de posse ao sesmeiro.

Diz Francisco Antônio de Souza casado e morador da Freguesia S. José de Taquary da Capitania de S. Pedro do Rio Grande do Sul, que esta de posse corporal de huma Data de mattos sita na margem Ocidental do rio Taquary com tres mil e duzentas e cinquenta de frente ao mesmo Rio e légua e meia para o sertão, confrontando pelo sul as Terra de José da Silva e Lima e seus irmãos [...] (PORTO ALEGRE, 1813, n.p).

$\mathrm{Na}$ sequência de doação de sesmarias em territórios do Taquari-Antas, aponta-se ainda a doação, em 1816, ao capitão Ricardo José Villa Nova. Conforme 
é possível observar no mapa das fazendas (Figura 1), feita pelo Conde de Rezende, em área que nos dias atuais está na jurisdição do município de Arroio do Meio, vale do Taquari.

Terras sitas na freguesia de Taquary, à margem do rio do mesmo nome, onde faz frente. Confrontam ao Sul com o arroio Forqueta; a Leste com o dito rio Taquary; ao Norte e Oeste com o sertão da Serra Geral (PORTO ALEGRE, 1816, n.p).

Transcorrido o primeiro momento de doações de sesmarias, a configuração social no Rio Grande do Sul e em áreas do Taquari-Antas caracterizava-se por uma rede de intensas trocas familiares. Sendo assim, a transferência das terras era feita por meio de herança ou compra. A maior parte das pessoas vivia a favor de parentes: sogros, pais e irmãos. Kuhn (2004) trabalha com as estratégias familiares nos Campos de Viamão e freguesias adjacentes no século XVIII, que “abrangiam a região dos rios Sinos, Caí e Taquari, onde havia 22 fogos. Seis anos depois, esta região se desmembraria da freguesia, constituindo-se na rica paróquia de Triunfo" (KUHN, 2004, p. 53), que, posteriormente, desmembrarse-ia e formaria o território do atual vale do Taquari, nos entornos da bacia hidrográfica do Taquari.

O mesmo autor ainda aponta que este grupo social se identifica por dois padrões distintos: um matrilinear, no qual a transmissão da herança se fazia pelas filhas, havendo uma sobrevalorização dos genros; o outro, patrilinear, no qual a transmissão patrimonial se fazia pelos filhos, embora alguns genros pudessem ser escolhidos. Tal situação indica que as terras nos entornos da bacia hidrográfica do Taquari-Antas já estavam quase todas ocupadas no início do século XIX, a exemplo das sesmarias mencionadas anteriormente, em posse de gente como o capitão Manoel Jesus Ferreira e Francisco Antonio de Souza, que possuíam sesmaria próxima ao atual município de Cruzeiro; José Ricardo Villa Nova, cuja sesmaria localizava-se em áreas do atual território de Arroio do Meio; João Inácio e José Inácio Teixeira, cuja jurisdição das sesmarias, respectivamente, englobava territórios dos atuais municípios de Lajeado e Estrela; e José da Silva Lima e seu irmão, com sesmarias no atual município de Cruzeiro.

Assim, a partir das décadas da primeira metade do século XIX, as terras no entorno da bacia hidrográfica do Taquari-Antas passaram adiante por meio de venda e compra. Portanto, uma expressiva parte deste território passou a ser ocupado também por não índios. Conforme o trabalho de Christilino (2004), alguns proprietários como Francisco Silvestre Ribeiro possuíam terras à margem direita da bacia hidrográfica do Taquari-Antas, próximo à fazenda denominada 
São Gabriel ${ }^{3}$, bem como, da margem esquerda, como é o caso da fazenda Estrela do Coronel Vitorino José Ribeiro, as quais podem ser observadas no mapa (Figura 1). Nos Autos de Medição da Fazenda Estrela, aparece o seguinte relato:

Dizem o Coronel Vitorino José Ribeiro e sua mulher Dona Ana Emilia de Sampaio Ribeiro, que sendo eles legítimos senhores e possuidores de uma Fazenda de cultura e mattos, denominada Estrella na qual residem, cita a margem esquerda do Rio Taquary, neste município, contendo trez mil e nove centos braços de frente ao referido rio, e légoa e meia de fundos para essa, com as divisas e confrontações indicados no respectivo Titulo de compra e confirmação que junto oferecem, cuja Fazenda a compra fizeram no ano de 1830 a José Inácio Teixeira Junior e sua mulher [...] (PORTO ALEGRE, 1860, n.p ).

No início do século XIX, o que atualmente é denominado de região do Vale do Taquari tomara certa relevância econômica em torno da produção de trigo, pois "esta foi uma atividade característica naquele período nas regiões de colonização açoriana” (CHRISTILINO, 2004, p. 41). Esta relevância econômica fica visível no alto índice de escravos que aparece no recenseamento de 1814, no qual aparecem 433 escravos de ambos os sexos. Nesse sentido, o modo de produção em territórios da bacia hidrográfica do Taquari-Antas estava de acordo com o contexto da Província de São Pedro, visto que, "no total, mais de 45\% da população era cativa, um percentual muito elevado, semelhante ao encontrado nas zonas mineradoras ou de plantation e não muito adequado a uma região voltada ao mercado interno" (KUHN, 2004, p. 51). Considerando a relevância das elites locais, os espaços nos entornos do Rio Taquari, em comparação a outros centros com arquitetura sofisticada e luxuosa da sociedade colonial e imperial, poderiam ser consideradas precárias, mas há outros aspectos que caracterizam "os privilegiados, outras formas de distinção social em um meio tão precário, como posse e acesso à terra e à propriedade escrava" (TIBURI, 2011 p. 51).

Contudo, a queda da economia em áreas da bacia hidrográfica do TaquariAntas decorre da estagnação da produção do trigo em meio ao fortalecimento de estabelecimentos comerciais e manufatureiros, que cresciam em função da implantação da agricultura voltada para as áreas de imigração alemã, a partir de 1824, que se instalou na província de São Pedro do Rio Grande do Sul. Outra fonte que alimentava a economia da época era a produção de tábuas de pinho e a erva-mate, produzida, principalmente, nas áreas mais altas, mas que também estava em decadência em virtude da exploração inadequada e também "em função da preferência da mesma oriunda do Paraguai" (CHRISTILINO, 2004, p. 44).

\footnotetext{
Fazenda que pertencia a José da Silva Lima e seus irmãos. Segundo Schierholdt (1993), a fazenda localizava-se onde atualmente encontra-se o município de Cruzeiro.
} 
Salienta-se que os espaços sulinos no Brasil no momento da ocupação lusa, por meio do estabelecimento de sesmarias eram fragmentados, tendo em vista que indígenas e colonizadores tinham concepções distintas de territorialidade. Destaca-se a já mencionada territorialidade Kaingang, que, segundo Laroque (2000), englobava boa parte das áreas do planalto sul, sentido bacia hidrográfica do rio Jacuí até a baliza fluvial do lago Guaíba. Há também a territorialidade Guarani, que se estendia desde a região de Misiones, nordeste argentino e leste do Paraguai até o litoral brasileiro, em áreas dos atuais estados do Rio Grande do Sul, Santa Catarina e do Paraná. Segundo Ladeira (2008), trata-se de um território de onde os grupos retiravam recursos necessários para a subsistência, como também onde viviam relações de sociabilidade.

Em relação às sesmarias, além do interesse pela ampliação do patrimônio fundiário, este território possibilitava outros interesses econômicos. Conforme Christilino (2004), a exploração da madeira de pinho até a década de 1850 era a principal fonte econômica das vilas localizadas em territórios da bacia hidrográfica do Taquari-Antas, tendo em vista a capacidade de translado pelas vias fluviais até a capital da Província, através dos rios Taquari e Jacuí. Além da produção da madeira, outro fator econômico importante era o da extração da erva-mate e das pedras, encontradas, principalmente, às margens do rio Taquari.

O avanço da conquista de territórios da bacia hidrográfica do TaquariAntas por parte do governo português, durante o período colonial e início do século XIX, trouxe uma nova configuração social para estes espaços.

\section{CONFLITOS ENTRE COLONIZADORES E INDÍGENAS KAINGANG EM TERRITÓRIOS DA BACIA HIDROGRÁFICA DO TAQUARI-ANTAS}

Apesar do avanço dos mecanismos das frentes de expansão, sejam elas motivadas por interesses espanhóis ou de portugueses, em direção aos territórios Kaingang, até o início do século XIX, acredita-se que grande parte do tradicional território destes indígenas manteve-se sem a presença dos colonizadores, pois o "[...] interior dos atuais estados do Paraná, Santa Catarina e o planalto riograndense continuaram sendo, durante o século XVIII e início do XIX, terra de índios" (MÉLIA apud LAROQUE, 2000, p. 58).

O planalto sul-rio-grandense, bem como, áreas localizadas nas bacias hidrográficas do Taquari-Antas e adjacências, eram tradicionais territórios dos indígenas Kaingang. Com base nos apontamentos do engenheiro Aphonse Mabilde (1983), que trabalhou como agrimensor nas estradas da província do 
Rio Grande do Sul, na primeira metade do século XIX, sabe-se que os Kaingang totalizavam aproximadamente 2000 pessoas.

Nesse contexto, ocorrem os primeiros contatos entre os Kaingang e os sesmeiros e fazendeiros, no decorrer da primeira metade do século XIX, em territórios das bacias hidrográficas do Taquari-Antas. Ou seja, de um lado, as sesmarias e fazendas que, desde fins do século XVIII, estendiam-se pelo território; por outro lado, intensificava-se o avanço da frente imigratória por meio de migrantes alemães, os quais acarretaram conflitos com os Kaingang, sobretudo, motivados pelos recursos naturais que eram utilizados para a subsistência indígena, conforme o mapa (Figura 2).

Figura 2 - Mapa indicando conflitos entre indígenas Kaingang e colonizadores em territórios da bacia hidrográfica do Taquari-Antas

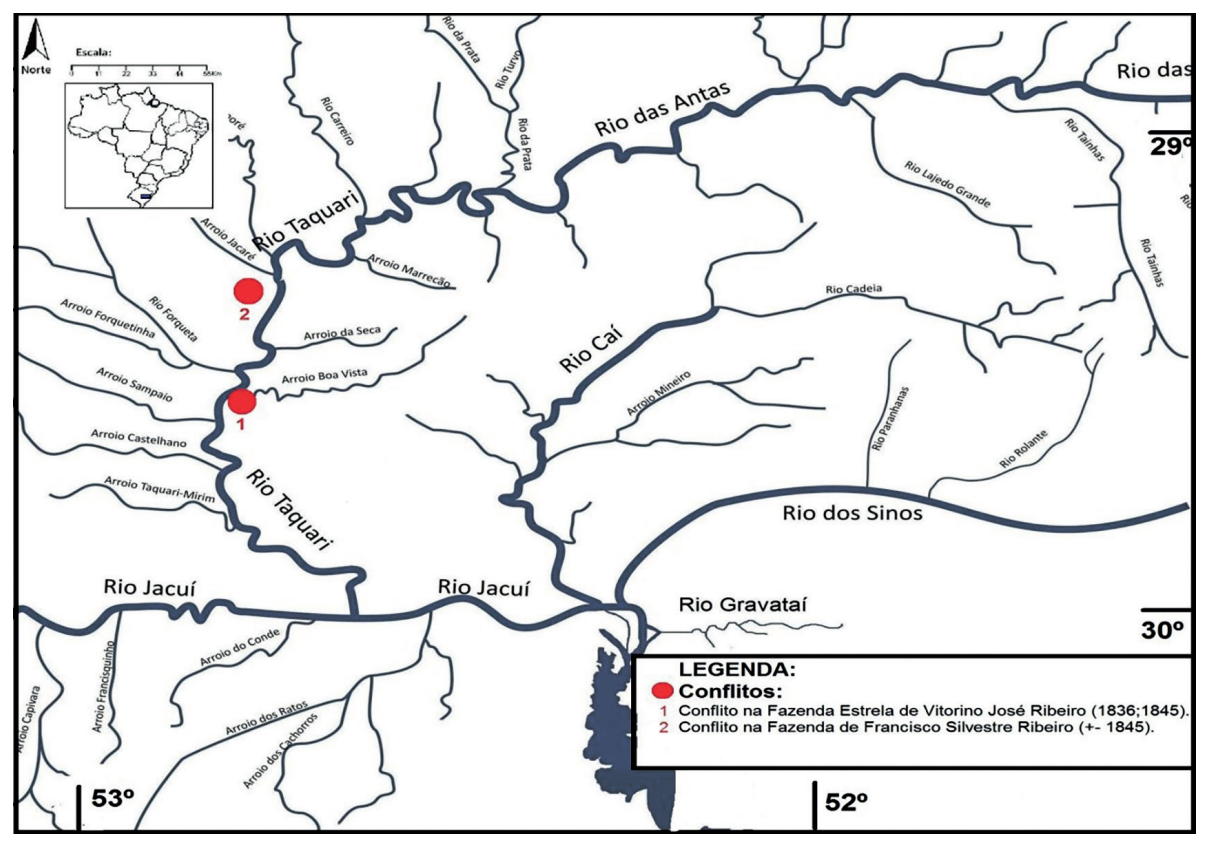

Fonte: Elaboração do autor a partir do software I3GEO. Disponível em: <http:/ / enola. procergs.com.br/i3geo/aplicmap/geral.htm?m2c66daoa26om3829hr615am01z.

A concepção territorial das sociedades ameríndias, como é o caso dos Kaingang, é bastante distinta das sociedades ocidentais. Visto que a noção de território engloba o âmbito cultural, as primeiras tinham uma noção mais coletiva acerca do uso do território, bem como uma ligação mais harmoniosa com o ambiente, seguindo suas ordens cosmológicas. As segundas seguiam uma noção mais voltada para o privado e de posse exclusiva, de uso irrestrito das 
riquezas naturais. Com base em Sahlins (1990), compreende-se que a cultura é tanto reproduzida como alterada na ação. Ou seja, grupos culturalmente distintos possuem processos históricos singulares e se constituem coletivamente a partir destes processos singulares. Com base nesta compreensão, devemos nos ater às concepções de territorialidades dos grupos em contato.

Portanto, neste cenário, redesenham-se relações conflituosas, pois se intensificam incursões guerreiras dos Kaingang sobre as fazendas estabelecidas em seus tradicionais territórios.

Illmo. e Exmo. Snr. Partecipo a V. Exa . que no dia 16 do que rege assisti a huma operação no corpo de hum pardo de nome Joze Antonio cuja operação consistia em tirar-se duas flexas que disem os conductores do dito pardo serem os bugre que lhe atirarão huma das flexas estava metida no peito direito, e outra no braço esquerdo; e logo que se acabou a operação elle faleceu; cujos bugres disem haverem sahido nos fundos da fazenda da estrela [...] (VIEIRA, 1836, n.p).

O fragmento documental ilustra um conflito no qual um pardo de nome Joze Antônio foi morto à flechada pelos Kaingang, possivelmente, um trabalhador das vastas terras da Fazenda Estrela, cujo proprietário, no período, era Vitorino José Ribeiro. A correspondência de 19 de dezembro de 1836, referida anteriormente, demonstra aspectos messiânicos de uma verdadeira cruzada contra os "infiéis".

Vale salientar que o imaginário do século XIX é marcado pelo discurso da "civilização versus barbárie", pensamento oriundo das teorias etnocêntricas surgidas na Europa, embasado em teorias que ampliavam o discurso de superioridade branca europeia sobre as populações consideradas periféricas (SANTOS, 2005). O documento a seguir apresenta informações sobre a organização de uma perseguição aos chamados “infiéis", isto é, os indígenas.

[...] e querendo mandar seguir a estes infiéis receby ao mesmo tempo hum officio do Sr. Juis Municipal para fazer seguir huma expedição de Cem. G. N. para se reunirem ao Tenente Coronel Antonio Manuel de Azambuja 09 me parece bastante difícil sahir este numero de gente pella divergência de opinioens que ainda reina, e pella falta de disciplina nas Companhias que se escondem aos avisos e mesmo respeito a ameaças que tenho sofrido aqui com tiros de oras em roda da povoação a que não posso descubrir quem seja tendo sido em vão todas as delingencias a esse respeito, e como os comprometidos deste lugar ainda se achão escondidos ou pellos subúrbios desta Freguezia ou por districtos visinhos por avisos que tenho tido, e que ainda tentão pela festa que esta mui próxima fazer reunioens para insultarem ou atacarem aos cidadãos legais desta Freguesia. Por estes 
motivos rogo a V. Ex haja de liberar a respeito pois me acho bastantemente confundido com o presente estado das coisas. Incluso remeto a V. $\mathrm{Ex}^{\mathrm{a}}$ hum pedido de muniçõens. Deus Guarde a V. Exa . (VIEIRA, 1836, n.p).

Os discursos e políticas indigenistas fizeram com que, de uma hora para outra, o indígena ocupante do seu tradicional território passasse a ser tratado pela lógica expansionista colonizadora como um invasor. Assim, o discurso "civilização versus barbárie" deslocava-se das palavras e do pensamento para a prática, onde qualquer um justificado pelo processo civilizatório estava autorizado a capturar e prender a população indígena (LAROQUE, 2000).

No cenário que se configurou, percebe-se que o choque entre diferentes concepções territoriais envolvendo estancieiros militares e Kaingang entrou em jogo no momento do contato. Por um lado, os estancieiros militares, aos se estabelecerem nos territórios, visavam à demarcação das fronteiras territoriais do Estado Nacional brasileiro que vinha se constituindo. Por outro lado, os Kaingang enfrentavam a gradual diminuição do seu espaço territorial, utilizado para a obtenção da subsistência. Vale ainda salientar que, conforme Clastres (2014), as guerras nas sociedades tradicionais têm um papel relevante, envolvendo prestígio e equilíbrio entre os grupos nativos; portanto, estas investidas guerreiras contra o colonizador no território em questão também precisam considerar as dinâmicas internas por prestígio, alianças e poder entre as próprias parcialidades Kaingang, conforme analisou Laroque (2000).

Outras incursões guerreiras por volta da década de 1840, nos entornos dos territórios localizados na bacia hidrográfica do Taquari-Antas, época em que se encontravam na jurisdição de Triunfo, são mencionadas na correspondência a seguir:

Illmº Senr= Accuzo a recepção do officio de V. S ${ }^{\text {a }}$ datado de 29 de Janeiro em o qual me ordena reúna os cidadãos deste Destricto que estejão nas circunstancias de marcharem contra os bugres que o tem invadido isto para serem dirigidos sob a ordem do Illmo Senr Delegado da Villa do Triunfo (ÁVILA, 1845, n.p).

Esta correspondência refere-se a conflitos nas fazendas de Vitorino José Ribeiro e Francisco Silvestre Ribeiro, conforme mapa (Figura 2), bem como, nas fazendas de Amaro Rodrigues e Ana Maria do Rosário. Sobre esses conflitos há o seguinte registro:

Em resposta tenho significar-lhe que logo dei execução as ordens de V. $\mathrm{S}^{\mathrm{a}}$ como se vê da cópia $\mathrm{N}^{\mathrm{o}} 1$, porem tendo apparecido os indígenas no dia 29 de Janeiro na Fazenda do cidadão Victorino José Ribeiro onde lhe assassinarão hum escravo que estava falquejando dezejava que alli fosse a 
entrada para serem perseguidos porem isto não se effectivou como se vê da cópia $\mathrm{N}^{\mathrm{o}} 2$ e eu nada pude fazer a bem da segurança daquella Fazenda e seus visinhos não só por que V. S $\mathrm{S}^{\mathrm{a}}$ se encarregou a perseguição dos selvagens ao Delegado do termo como porque houve falta de armamento e munição para semelhante delingencia. Não posso deixar de significar a V. $S^{a}$ que não mi consta que este Districto fosse invadido pelos selvagens, antes do dia 29 de Janeiro dia em que V. S ${ }^{a}$ datou seo Officio, e que a requisição foi feita por prevenção para guardar-se lugares que o ano passado forão amiaçados e que por isso fiquei privado de fazer a perseguição onde elles apparecerão por estar esperando que seria attendida a requisição que fis ao mesmo Delegado. V. S $\mathrm{S}^{\mathrm{a}}$ deve estar ao facto que os selvagens todos os veroens costumão descer a serra e atacar as habitações dos pacíficos moradores, não só deste districto como do Cahy, Santo Amaro e como ultimamente aconteceo nas Fazendas de Francisco Silvestre Ribeiro, Maria Francisca do Rosário, Amaro Rodrigues, (ÁVILA, 1845, n.p).

Esta correspondência de Francisco Mathias de Souza e Ávila, subdelegado de polícia, ao Dr. Manoel Jose de Freitas Travassos, Juiz de Direito e Chefe de Polícia da Província, evidencia, em primeiro lugar, um estado conflituoso nos territórios localizados na bacia hidrográfica do Taquari-Antas. Como visto, em meados da última década da primeira metade do século XIX, houve uma intensificação das incursões Kaingang, em áreas que o documento identifica como encosta da serra.

[...] e outros e por isso se torna muito necessário que o Governo da Província tome em consideração estes acontecimentos, e para proebilos bom será que se crie hua companhia somente destinada para este fim e que esteja reunida nos mezes de Dezembro, Janeiro, Fevereiro e Março, afim de andarem a acodir a qualquer ponto que for ameaçado afim de evitar o damno, e mesmo sendo elles batidos não se apresentarão tão ousados como ultimamente tem accontecido, isto devido ao nenhum cazo que se tem feito de seus estragos causados aos moradores. Emquanto porem esta medida, ou outra que o governo achar conveniente, senão adopta espera que V. $S^{a}$ dê suas providencias para que me seja remettido algum armamento e mesmo ordem para reunir os cidadãos para prevenir o mal que todos os dias se espera, pois neste momento acabo de receber participação que elles apparecerão hontem na Fazenda de Miguel José de Cordero, e e pelos indícios que se conhece que andão em grande porção e que tem percorrido toda a Costa da Serra. Espero que V. Sa tome isto em consideração por que todos os moradores da Costa da Serra estão amendrotados, e alguns já tem abandonado suas habitaçoens. Deos Guarde a V. Sa. Taquari 15 de fevereiro de 1845. Illmº Senr. Dr. Manoel José de Freitas Travassos Juis de Direito e Chefe de Policia da Província. Francisco Mathias de Sousa e Ávila, Subdelegado de Policia (ÁVILA, 1845, n.p). 
Conforme visto, a diminuição do espaço para a obtenção de subsistência em virtude dos avanços da frente de expansão, somados à compreensão do uso coletivo dos espaços naturais por parte dos Kaingang, oposto ao colonizador que é privado, tiveram significativa influência nos conflitos gerenciados pelos Kaingang, principalmente, durante o verão, conforme informações da correspondência de 15 de fevereiro de 1845, por ser o período da colheita de milho e de outros produtos agrícolas.

Nesse sentido, a análise de Dornelles (2011) em relação aos conflitos com os imigrantes que se encontravam em territórios da bacia hidrográfica do Caí se aproxima do que ocorre nos territórios da bacia hidrográfica do Taquari-Antas. Com base neste contexto e no estudo de Laroque (2000), há indicativos de que as parcialidades Kaingang lideradas por Doble, Braga e Nicué são as que ocupavam territórios de ambas as bacias.

Como características gerais desses assaltos se podem observar, em primeiro lugar, o saque às roças de milho que se encontravam prontos para colheita, por isso, a maior parte das investidas indígenas ocorreu nos primeiros meses do ano. Durante o inverno, os Coroados mantinhamse envolvidos na coleta e processamento dos pinhões, principal alimento deste grupo, realizados pelas mulheres (DORNELLES, 2011, p. 31).

Somos levados a crer que as incursões guerreiras Kaingang intensificaramse em meados do século XIX, nos territórios em análise, por estarem nas proximidades de áreas de terras devolutas ${ }^{4}$. Como salientado nos trabalhos de Laroque (2000) e Ladeira (2008), a territorialidade, tanto Kaingang como Guarani, que predominava no sul do Brasil Meridional até a chegada do europeu não perpetuava a posse exclusiva das terras como um bem exclusivo. Tratava-se de áreas de significação coletiva de onde também retiravam a sua subsistência. Essa concepção, para o homem branco, era incompreensível; por isso, reportavamse aos territórios indígenas como "terra de ninguém. Corrobora para a questão que, em áreas da bacia hidrográfica do Taquari-Antas, observa-se o aumento da legitimação de terras e a expansão dos patrimônios fundiários. Sobre isto Christilino (2004) nos informa:

Nesse mesmo sentido podemos observar que as primeiras legitimações de terras no Vale do Taquari ocorreram nestas proximidades (fundos da Fazenda Estrela), visando assegurar as suas possessões frente à expansão da colonização, o que traria a segurança em torno da posse ou título reconhecidos (CHRISTILINO, 2004, p. 179).

\footnotetext{
Terras consideradas vazias sob domínio do Estado brasileiro, apesar de estarem ocupadas por populações indígenas ou mesmo pobres lavradores não reconhecidos como donos.
} 
Outro episódio envolvendo conflitos com os Kaingang ocorreu na fazenda de posse do capitão Francisco Silvestre Ribeiro, localizada à margem direita do rio Taquari, conforme o mapa (Figura 2). No auto de medição do seu genro Joaquim Alves Xavier, datado de 1887, aparecem as seguintes informações:

Translado da publica forma constante dos autos de medição de posse de Joaquim Alves Xavier, sua mulher e outros, sob numero dois mil e desesete, a folhas seis dos mesmos autos: D. Ana de Oliveira Sallasar Ribeiro viúva do Capitão Francisco Silvestre Ribeiro dá ao Registro Terras e mattos que seu finado marido obteve por concessão do Governo em desesseis de Março de mil oitocentos e quarenta e seis sitaas no fundo da Fazenda da mesma senhora denominada S. Caetano na margem direita do rio Taquary com frente ao sul fundos ao Norte ao arroio Jacaré desviando-se pelo Leste com as vertentes que desaguam no rio Taquary e pelo Oeste com o arroio da Forqueta. Villa de Taquary quinze de hulho de mil oitocentos e cinquenta e seis. Ana de Oliveira Sallasar Ribeiro (PORTO ALEGRE, 1887 , n.p).

Conforme o documento, as terras do capitão Francisco Silvestre Ribeiro localizavam-se onde atualmente é o município de Encantado, no vale do Taquari. Não encontramos maiores informações deste conflito com os indígenas, mas cogitamos que tenha sido para a obtenção de algum produto cultivado nesta fazenda, ou somente pelo fato de estarem estabelecidos em território Kaingang. Em nosso ponto de vista, é bem provável que se houvesse alguma morte, esta estaria registrada, já que a Correspondência de 15 de fevereiro de 1845, encaminhada por Francisco Mathias de Sousa e Ávila, subdelegado de polícia de Taquari, para Manoel José de Freitas Travassos, chefe de polícia da Província, é apelativa por mais segurança. A questão que fica é o que teria ocasionado este conflito à margem direita do rio Taquari, visto que, neste período, é o único que está registrado. Uma possibilidade que aventamos com base nos levantamentos arqueológicos apresentados por Wolf (2012) em áreas do rio Forqueta, bem como, considerando as movimentações indígenas pelo tradicional território, independente dos avanços da frente de expansão com o estabelecimento de fazendas, movimentar-se pelo tradicional território faz parte da cultura Kaingang. Segundo Clastres ([1974] 2013), as sociedades denominadas de primitivas (tradicionais) caracterizavam-se pela abundância de recursos necessários para a sua subsistência, sem a necessidade de acumulação. Esse pressuposto é possível de aplicar aos Kaingang no século XIX, pois nos parece que os conflitos ocorrem justamente quando os tradicionais espaços de caça e coleta passam a ser ocupados pelos não índios. 


\section{CONSIDERAÇÕES FINAIS}

Considera-se que os conflitos registrados entre os Kaingang e a frente de expansão em territórios da bacia hidrográfica do Taquari-Antas façam parte de um mesmo avanço, divididos em duas frentes: esta, em direção ao rio Taquari; e a outra, em direção ao rio Caí. A primeira caracteriza-se pelo apoio da coroa e do Império em estabelecer ocupações ao longo da bacia; a segunda, pelo incentivo do Império em estabelecer imigrantes alemães ao longo da bacia do Caí. Compreendendo a dinâmica histórica de ocupação do tradicional território Kaingang e pela maneira como o grupo o concebe e relaciona-se com ele, destacam-se as suas fronteiras, tendo como base a lógica cultural dos grupos envolvidos. A guerra, segundo a dinâmica cultural Kaingang, no que diz respeito à manutenção territorial, expressou-se em forma de conflitos em relação aos integrantes das fazendas estabelecidas em territórios da bacia hidrográfica do Taquari-Antas.

Considera-se, de forma preliminar, a manutenção cultural dos Kaingang em relação à diminuição do seu espaço territorial, abrindo espaço para ressignificações no campo da própria lógica das negociações no que diz respeito à manutenção territorial. Segundo Barth ([1969] 2000), passíveis de acontecer, mas que no todo possibilitam o fortalecimento de aspectos culturais, em virtude do reconhecimento de pertença a um determinado grupo em consequência do contato com o outro considerado diferente; portanto, é o que ocorreu por partes dos indígenas Kaingang e dos colonizadores analisados.

Pode-se considerar que os conflitos ocorreram em virtude do contato entre diferentes concepções territoriais. A concepção indígena, mais fluida, que não reconhece a propriedade privada, isto é, os recursos disponíveis no território são coletivos; a outra concepção de territorialidade, a do colonizador, cuja visão era utilitarista e visava fins econômicos para atender o projeto colonial português.

\section{REFERÊNCIAS}

ÁVILA, Francisco Mathias de Souza. Correspondência do subdelegado de polícia de Taquari. Destinatário: Juiz de direito e chefe de Polícia da Província do Rio Grande do Sul Manoel José de Freitas Travassos. Taquari, 15 fev. 1845. Arquivo Histórico do Rio Grande do Sul, Porto Alegre. Corpo Policial. Documento Avulso, Maço 57. 
BARTH, F. Os grupos étnicos e suas fronteiras. In: BARTH, Frederik. LASK, Tomke (Org.). O Guru, o iniciador e outras variações antropológicas. Trad.: John Cunha Comerford. Rio de Janeiro: Contracapa, [1969] 2000. p. 25-67.

CAVALCANTE, T. L. V. Etno-história e história indígena: questões sobre conceitos, métodos e relevância da Pesquisa. História, São Paulo, v. 30, n. 1, p. 349-371, jan./jun. 2011.

CHRISTILINO, C. Estranhos em seu próprio chão: o processo de apropriações de terras na Província de São Pedro do Rio Grande do Sul (o Vale do Taquari no período de 1840-1889). 2004. 374 f. Dissertação (Mestrado em História da América Latina) - UNISINOS, São Leopoldo-RS, 2004.

CLASTRES, P. A sociedade contra o Estado. São Paulo: Cosac Naify, [1974] 2013.

Arqueologia da violência: pesquisas de antropologia política. São Paulo: Cosac Naify, 2014.

DORNELLES, S. S. A história em As vítimas do bugre, ou como tornar-se bugre na História. Anos 90, Porto Alegre, v. 18, n. 34, p. 245-278, dez. 2011. Disponível em: https://seer.ufrgs.br/anos90/article/view/24028. Acesso em: 15 maio 2017.

FARINATTT, L. A. Confins Meridionais: famílias de elite e sociedade agrária na Fronteira Sul do Brasil (1825-1865). 2007. 421f. Dissertação (Programa de Pós-Graduação em História Social) - Universidade Federal do Rio de Janeiro, Rio de Janeiro, 2007.

GORENDER, J. O escravismo colonial. 6. ed. São Paulo: Editora Ática, 1992.

KÜHN, F. Gente da fronteira: sociedade e família no sul da América portuguesa - século XVIII. In: GRIJÓ, L. A. KUHN, F. GUAZZELI, C. A. (Orgs.) Capítulos de história do Rio Grande do Sul. Porto Alegre: Editora da UFRGS, 2004. p. 47-75.

Breve história do Rio Grande do Sul. 3. ed. Porto Alegre: Leitura XXI, 2002.

LADEIRA, M. I. Espaço geográfico Guarani-Mbya: significado, constituição e uso. São Paulo: EdUSP, 2008.

LAROQUE, L. F. da S. Lideranças Kaingang no Brasil Meridional (1808-1889).

Pesquisas. Antropologia, São Leopoldo, n. 56, 2000. 
LAROQUE, L. F. da S.; MACHADO, N. T. G.; JASPER, A.; ZANON, L. Etnohistória como abordagem interdisciplinar no estudo de populações indígenas Guarani. Boletim de Geografia, Maringá, v. 33, p. 168-183, 2015. Disponível em: <http://www.periodicos.uem.br/ojs/index.php/BolGeogr/article/view File/22078/pdf_78>. Acesso em: 15 jan. 2018.

MABILDE, P. F. A. Booth. Apontamentos sobre os indígenas selvagens da Nação Coroados dos matos da província do Rio Grande do Sul - 18361866. São Paulo: IBRASA, 1983.

OSÓRIO, H. Estrutura agrária e ocupacional. In: BOEIRA, N, GOLIN, T. Colônia (Coleção História Geral do Rio Grande do Sul). Passo Fundo: Méritos, 2006. v. 1. p. 153-170.

PESAVENTO, S. J. A Revolução Farroupilha. São Paulo: Editora Brasiliense, 1986.

PORTO ALEGRE (RS). Arquivo Público do Estado do Rio Grande do Sul. Sinopse das concessões de sesmarias na Capitania de São Pedro do Rio Grande do Sul. Carta disposição da sesmaria [de] Francisco Machado Fagundes da Silveira, concedida por Gomes Freire de Andrade no ano de 1762. Carta - Livro n. 3, fl. 204. 1762.

Arquivo Público do Estado do Rio Grande do Sul. Sinopse das concessões de sesmarias na Capitania de São Pedro do Rio Grande do Sul. Carta disposição da sesmaria [de] Francisco da Silva, concedida por José Marcellino de Figueiredo no ano de 1780. Carta - Livro n. 9, fl. 65v. 1780.

Arquivo Público do Estado do Rio Grande do Sul. Sinopse das concessões de sesmarias na Capitania de São Pedro do Rio Grande do Sul. Carta disposição da sesmaria [de] José da Silva Lima e seus irmãos, concedida pelo Conde de Rezende no ano de 1798. Carta - Livro n.10, fl. 138. 1798.

Arquivo Histórico do Rio Grande do Sul. Fundo Sesmarias. Carta que comprova a doação de sesmaria a João Ignácio Teixeira em 1800. Carta Avulsa. 1800.

Arquivo Público do Estado do Rio Grande do Sul. Sinopse das concessões de sesmarias na Capitania de São Pedro do Rio Grande do Sul. Carta disposição da sesmaria do Capitão Manoel Jesus Ferreira, concedida pelo Conde de Rezende no ano de 1800. Carta - Livro n. 9, fl. 233. 1800.

Arquivo Histórico do Rio Grande do Sul. Fundo Sesmarias. Carta petição de sesmaria por parte [de] Francisco Antônio de Souza no ano de 1809. Carta - Avulsa. 1809. 
Arquivo Histórico do Rio Grande do Sul. Fundo Sesmarias. Carta que comprova a doação de sesmaria a Francisco Antônio de Souza no ano de 1813. Carta - Avulsa. 1813.

Arquivo Histórico do Rio Grande do Sul. Fundo Sesmarias. Carta que comprova a doação de sesmaria a Francisco Antônio de Souza no ano de 1813. Carta - Avulsa. 1813.

Arquivo Público do Estado do Rio Grande do Sul. Sinopse das concessões de sesmarias na Capitania de São Pedro do Rio Grande do Sul. Carta disposição da sesmaria [de] Ricardo José Villa Nova, concedida pelo Conde de Rezende no ano de 1816. Carta - fl. 349. 1816.

Arquivo Histórico do Rio Grande do Sul. Fundo Lei de Terras de 1850. Auto de medição [dos] proprietários Vitorino José Ribeiro e Anna Emilia Sampaio Ribeiro. Auto de medição n. 12. 1860.

Arquivo Histórico do Rio Grande do Sul. Fundo Lei de Terras de 1850. Auto de medição [de] autoria de Joaquim Alves Xavier, Estrela. Auto de medição n. 2017. 1887.

SAHLINS, M. Ilhas de História. Rio de Janeiro: Jorge Zahar, 1990.

SANTOS, R. J. Antropologia para quem não vai ser antropólogo. Porto Alegre: Ed Tomo editorial, 2005.

SCHIERHODLT, J. A. Lajeado: V. 1: povoamento, colonização, história política. 2. ed. Lajeado-RS: Prefeitura Municipal de Lajeado, 1993.

TIBURI, M. Charqueadores, estancieiros e vereadores: elites econômicas e políticas nas margens do Jacuí (São Jerônimo - XIX). Porto Alegre: Companhia Rio-Grandense de Artes Gráfica (CORAG), 2011.

VIEIRA, João Tristão de. [Correspondência do Comandante de Polícia de Taquary]. Destinatário: Presidente da Província do Rio Grande do Sul Joze de Araújo Ribeiro. Taquary, 19 dez. 1836. Arquivo Histórico do Rio Grande do Sul, Porto Alegre. Corpo Policial. Documento Avulso, Maço 144.

WOLF, S. Paisagens e sistemas de assentamento: um estudo sobre a ocupação humana pré-colonial na bacia hidrográfica do rio Forqueta-RS. 2012. 180 f. Dissertação (Mestrado em Ambiente e Desenvolvimento) - Centro Universitário Univates, Lajeado-RS, 2012. 